\section{CAEP C4 SEPSIS GUIDELINES}

To the editor: Severe sepsis and septic shock continues to present major challenges to emergency physicians (EPs) across Canada. I have had the opportunity over the last year to speak with many EPs in both large and small centres, and for the most part, there is interest and momentum to address the needs of these patients when they present to the emergency department (ED). However, there are abundant challenges, which, to some extent, were anticipated when the CAEP Critical Care Interest Group prepared the recent sepsis guidelines. ${ }^{1}$

One of the most frequent issues that have been articulated is that the time and effort required to provide optimal care for these patients distracts the EP from attending to other patients in the ED. My simple response: "Too bad, this patient needs you more." Let's put it this way: the mortality rate for severe sepsis or septic shock (at $30 \%-50 \%$ ) eclipses that of almost any other ED patient. In addition, the care that an EP provides can make an immediate, and perhaps the most significant, impact on the septic patient's outcome. Optimal care, including identification, appropriate antimicrobial administration, aggressive resuscitation and source control is well within the expertise of our specialty and substantially improves a septic patient's chances of survival. I think that we would be hard-pressed to say that the "next patient" that we leave our sepsis patient to see will benefit from our care in a similar manner.

Another issue that has been raised is that other consultants (e.g., medicine, surgery and critical care) do not have the same interest in the early aggressive management of these patients as we do. This is certainly disappointing but not surprising. There continues to be a gap in the appreciation of the importance of the optimal management of severe sepsis among specialties. However, we cannot assume that our colleagues are as knowledgeable in this area as the Canadian emergency medicine community, and we should take the lead in educating our peers. Institutional protocols for the management of sepsis, which can be applied to both the patient in the ED or in the ward, would benefit not only patients, but also improve this educational process. A summary of the recommendations was not included in the guidelines, but is available at www.cjem-online.ca/v11 /n4/sepsis-guidelines.

The CAEP Sepsis Guidelines were intended to provide a skeleton around which centres can build to individualize their approach to these patients. Not all the recommendations can be followed in every centre (including my own). However, this topic is important and will not go away. I urge the Canadian emergency medicine community to develop local protocols for our severe septic and septic shock patients to maximize their chances of recovery.

\section{Robert Green, BSc, MD}

Associate Professor, Emergency Medicine and Critical Care Medicine, Dalhousie University, Halifax, NS

\section{Reference}

1. Green RS, Djogovic D, Gray S, et al. Canadian Association of Emergency Physicians sepsis guidelines: the optimal management of severe sepsis in Canadian emergency departments. CJEM 2008;10:443-59.
Letters will be considered for publication if they relate to topics of interest to emergency physicians in urban, rural, community or academic settings. Letters responding to a previously published CJEM article should reach CJEM head office in Vancouver (see masthead for details) within 6 weeks of the article's publication. Letters should be limited to 400 words and 5 references. For reasons of space, letters may be edited for brevity and clarity.
Les lettres seront considérées pour publication si elles sont pertinentes à la médecine d'urgence en milieu urbain, rural, communautaire ou universitaire. Les lettres en réponse à des articles du JCMU publiés antérieurement devraient parvenir au siège social du JCMU à Vancouver (voir titre pour plus de détails) moins de 6 semaines après la parution de l'article en question. Les lettres ne devraient pas avoir plus de 400 mots et 5 références. Pour des raisons d'espace et par souci de concision et de clarté, certaines lettres pourraient être modifiées. 